\title{
LA CODIFICACIÓN DEL DERECHO PRIVADO (DERECHO CIVIL Y DERECHO COMERCIAL) EN HUNGRÍA Y EL NUEVO CÓDIGO CIVIL HÚNGARO DEL 2013
}

\author{
GÁBOR HAMZA \\ Catedrático. Miembro Numerario de la Academia de Ciencias Húngara \\ Universidad "Eötvös Loránd" de Budapest
}

Resumen: El presente estudio pretende ofrecer un panorama sobre las diversas etapas de la codificación del Derecho privado (Derecho civil y Derecho comercial) en Hungría, así como de las características del (segundo) Código Civil Húngaro del 2013.

Palabras clave: Codificación del Derecho civil húngaro; Código Civil Alemán; Código Civil Francés, Código Civil Húngaro del 1959; Código Civil Húngaro del 2013; Código Civil Suizo; Código Suizo de Obligaciones; Escuela Pandectista alemana del derecho; Proyecto del Código Civil del 1928; proyectos del código civil húngaro.

\begin{abstract}
The first part of the paper is dealing with the historical development of the codification of private law (both civil law and commercial law) in Hungary. The author points out the influence of Roman law and the German Pandectist legal science on the different drafts of the Hungarian civil code. The drafters of the Hungarian civil code took into account the French Civil Code, the Swiss Code of Obligations, the German Civil Code and the Swiss Civil Code. In the second part of the study the author describes the characteristic features of the first Hungarian Civil Code promulgated in 1959. Regarding the second Hungarian Civil Code adopted in 2013, the author emphasizes that the drafters succeeded in bringing it into compliance with the current trends of civil law related codification in the European Union (EU) in relation both to its structure and its basic concept (concept moniste).
\end{abstract}


Keywords: Codification of the Hungarian civil law; Draft of the Hungarian Civil Code of 1928, drafts of the Hungarian civil code; French Civil Code; German Pandectist legal science; Hungarian Civil Code of 1959; Hungarian Civil Code of 2013; Swiss Civil Code; Swiss Code of Obligations.

SUMARIO: I. PANORAMA HISTÓRICO. II. EL CÓDIGO CIVIL DEL 2013

\section{PANORAMA HISTÓRICO}

1. El presente estudio pretende ofrecer un panorama sobre las diversas etapas de la codificación del Derecho privado (Derecho civil y Derecho comercial) en Hungría, así como de las características del (segundo) Código Civil Húngaro del 2013.

Como introducción al panorama general sobre la codificación del Derecho civil en Hungría, se debe indicar que la vida jurídica del Reino de Hungría ("Regnum Hungariae”) experimentó un cambio radical por influencia de la Escuela Histórica del Derecho alemana. Este punto de inflexión se manifestó inicialmente a través del primer gran jurista del Derecho privado del siglo XIX en Hungría, Ignác Frank (1788-1850), que se mostró, como Friedrich Carl von Savigny (1779-1861), contrario a la codificación del Derecho privado. El encomiable jurista húngaro László Szalay (18131864) describe a su contemporáneo Ignác Frank como el "guía de una nueva era".

Ignác Frank, en su obra publicada en 1823, titulada Specimen elaborandarum institutionum iuris civilis Hungarici, aplicó conceptos y construcciones del Derecho romano -que también aparecen en otros de sus trabajos- con la finalidad de explicar las relaciones reales sobre inmuebles en Hungría. Un comprometido seguidor de los postulados de la Escuela Histórica del Derecho lo fue también Ignác Frank, discípulo de Gusztáv Wenzel (1818-1891), en cuya obra resulta posible encontrar un gran número de referencias al Derecho romano clásico y justinianeo.

2. A partir de la mitad del siglo XIX, la Pandectística alemana comenzó a ejercer una importante y creciente influencia en las Ciencia jurídica y en la práctica judicial húngara. La mayoría de los romanistas y iusprivatistas húngaros fueron discípulos de los pandectistas alemanes. El más renombrado discípulo húngaro de Rudolf von Jhering (1818-1892) fue el destacado romanista y iusprivatista Gusztáv Szászy-Schwarz (18581920). Mihály Biermann (1848-1889) -profesor de la Academia de Derecho en Győr, y, más tarde, de la Academia de Derecho en Nagyszeben- asistió a las clases de Rudolf von Jhering en Göttingen. El gran jurista, especialista en Derecho comparado e 
internacionalmente reconocido, Elemér Balogh (1881-1953), fue discípulo de Heinrich Dernburg (1829-1907) en Berlín. A través de su actividad literaria, estos y otros juristas húngaros impulsaron la recepción de elementos de la pandectística alemana en la ciencia jurídica húngara.

3. Tras el fracaso de la codificación del Derecho privado comenzó el intento del hegeliano y decisivo opositor de las ideas escépticas sobre la codificación de Savigny, László Szalay, con la finalidad de codificar el Derecho privado húngaro sobre los fundamentos del Code Civil francés del 1804, considerado por aquél como la máxima expresión de la codificación. Este intento, sin embargo, estaba condenado al fracaso, ya que el Code Civil francés, como posible modelo de Código Civil, no resultaba aceptable en la Hungría del momento, ante todo por razones políticas e ideológicas. ${ }^{1}$

Resulta preciso destacar que en la época de las reformas, numerosos sectores del Derecho privado en sentido amplio habían sido objeto de regulación legal en el reino de Hungría; por ejemplo, en el ámbito del Derecho comercial y concursal.

4. A impulso de la Revolución y la Guerra de la Independencia en 1848/1849, se promulgó la ley 1848: XV, que fundamentalmente tuvo por objeto derogar la que regulaba el Derecho de sucesiones feudal y anunciar la codificación del Derecho privado.

A los efectos de preparar la codificación, el entonces renombrado jurista, destacado estadista y por entonces Ministro de justicia Ferenc Deák (1803-1876) creó en el "Ministerio de Justicia" (entiéndase por tal una sección del por entonces Ministerio único) un área dedicada a la codificación. Deák fijó como tareas, entre otras, la redacción de los "códigos penal, civil y de minería". Inicialmente se encargó la dirección de dicha sección al propio László Szalay, como lo aclara una carta de Szalay enviada desde Frankfurt am Main (donde él, por aquel entonces, formaba parte de una misión diplomática alemana para la Asamblea Nacional). Szalay no pudo entregar el proyecto a la Asamblea Nacional húngara convocada el 2 de julio de 1848. Un escueto expediente es lo único que consta al respecto en el material de archivo del "Ministerio de Justicia".

La consecuencia fue el fracaso de este tercer intento de codificación, ante todo por los sucesos históricos acaecidos posteriormente, y más en especial por el fracaso del movimiento independentista húngaro.

5. Después de la derrota de la Revolución y de la Guerra de la Independencia en agosto de 1849, en el año 1853, entró en vigor en Hungría (y varios meses después, el 1 de septiembre de 1853, también en Transilvania), mediante una disposición real, el Código Civil General austriaco ("Allgemeines Bürgerliches Gesetzbuch für die gesammten deutschen Erbländer der Oesterreichischen Monarchie"; abreviado: ABGB.). El primer

\footnotetext{
${ }^{1}$ Sobre las características del Código civil francés véase: W. WILHELM, Gesetzgebung und Kodifikation in Frankreich. Ius Commune 1 (1967) y A.-J. ARNAUD, Origines doctrinales du Code civil français. Paris, 1969.
} 
código civil moderno en Europa, el ABGB, que precisó más de cuarenta años de trabajo, fue realizado por tres generaciones de destacados juristas: Joseph Ritter von Azzoni (1712-1760); Johann Bernhard Ritter von Zenker (1720-1765); Johann Bernhard Horten (1735-1786); Franz Georg Ritter von Kess (1747-1799); y Karl Anton von Martini (1726-1800). Karl Anton von Martini ${ }^{2}$ consiguió culminarlo en 1797 con el Westgalizisches Gesetzbuch, siendo promulgado ese mismo año por el emperador Francisco II (1792-1835) ${ }^{3}$. Con posterioridad a la muerte de Karl Anton von Martini, su discípulo Franz von Zeiller (1751-1828) ${ }^{4}$-denominado "Schöpfer des Allgemeinen Bürgerlichen Gesetzbuches"- fue encargado por el emperador de redactar una versión revisada, el Allgemeines Bürgerliches Gesetzbuch, que fue promulgado en 1811 para todos los terrtorios de habla alemana de la monarquía de la Casa de los Habsburgo y posteriormente extendido a Lombardía y a otros lugares. Del mismo también se hizó una version en idioma húngaro.

6. El restablecimiento del sistema constitucional en la Hungría monárquica, equiparable a una constitución política, se realizó a través del llamado "Diploma de Octubre" en el año 1860. De conformidad con lo dispuesto en el "Diploma de Octubre", la competencia legislativa para la codificación del ordenamiento jurídico quedó reservada a la Dieta o al Consejo Real. Así, se convocó a una Conferencia de la Asamblea de Justicia en Sopron. La conferencia tomó la iniciativa de llevar adelante la reforma del Derecho privado húngaro sobre bases nacionales. ${ }^{5}$

Uno de los miembros de esta Conferencia de Justicia fue, entre otros, György Zsivora (1804-1883) ${ }^{6}$, partidario del mantenimiento del Código Civil General austriaco, aunque con la introducción en el mismo de algunas modificaciones. Estas modificaciones deberían, a su entender, contemplar las características particulares del desarrollo jurídico húngaro.

7. En el año 1861, la Conferencia de Justicia emitió las Reglas Provisorias de la Justicia. Hasta la promulgación de dichas Reglas, el ABGB. austríaco había estado en vigor. Por otra parte, debe tenerse también en cuenta que el Código Civil General austriaco continuó vigente en algunas partes de Hungría, por ejemplo, en el histórico

\footnotetext{
${ }^{2}$ Véase: M. HeBeIS, Karl Anton von Martini 1726-1800. Leben und Werk. Frankfurt am Main, 1996.

3 Véase: W. BRAUNEDER, Europas erste Privatrechtskodifikation: Das galizische Bürgerliche Gesetzsbuch, en Barta, Heinz et alii Naturrecht und Privatsrechtskodifikation. Martini Colloquium 1998, Wien, 1999. Sobre la codificación austriaca véase: W. BRAUNEDER, Das Allgemeine Bürgerliche Gesetzbuch für die gesammten Deutschen Erbländer der österreichischen Monarchie von 1811, en Gutenberg-Jahrbuch 62, Mainz, 1987.

${ }^{4}$ Véase: J. F. DESPUT - G. KOCHER: Franz von Zeiller: Symposium der Rechtswissenschaftlichen Fakultät der Universität Graz und der Steiermärkischen Landesbibliothek am 30. November 2001 aus Anlass der 250. Wiederkehr seines Geburtstages. Graz, 2003 y B. SCHILLER, Franz Anton von Zeiller als Gesetzgeber und Begründer einer bürgerlichen Rechtskultur. en K. ACHAM (ed.): Rechts-, Sozial- und Wirtschaftswissenschaften aus Graz. Wien, 2011. pp. 289-312.

5 Véase G. HAMZA: Entstehung und Entwicklung der modernen Privatrechtsordnungen und die römischrechtliche Tradition. Budapest, 2009. pp. 381-388.

${ }^{6}$ György Zsivora tuvo a su cargo altas funciones judiciales: en el año 1861 fue juez en la Tabula Septemviralis; entre 1869 y 1873 fue ministro presidente de la Curia Real (máximo tribunal en Hungría tras el compromiso austro-húngaro en el año 1867). Véase: L. TóTH, Emlékbeszéd Zsivora György felett ["Discurso en memoria de György Zsivora"] Budapest, 1884.
} 
Siebenbürgen ("Transylvania") ${ }^{7}$. Ello fue debido a que ese territorio, en virtud del Compromiso austro-húngaro del año 1867, permaneció bajo la administración central austriaca. La reiniciación de los trabajos preparatorios para la codificación del Derecho privado para la totalidad del territorio estatal húngaro debió esperar hasta el Compromiso austro-húngaro.

8. La Asamblea Nacional (Dieta) convocada el 10 de diciembre de 1865 acordó iniciar la elaboración de un Código Civil húngaro. En el año 1870, en el primer Congreso Nacional de Juristas de Hungría se propuso que entrara nuevamente en vigor, aunque de forma provisional, el Código Civil General austriaco (ABGB). Por aquél entonces se puso de manifiesto, en especial por Imre Hódossy (1840-1909), que solamente era necesaria la reforma en un diez por ciento del texto de ese cuerpo legal. Otros juristas, por el contrario, como por ejemplo ocurrió con Antal Rentmeister (1837-1908), seguidor de la Escuela Histórica del Derecho, resaltaron la importancia de conservar el antiguo Derecho patrio húngaro. Por su parte, Rezső dell'Adami (1850-1888) destacó que también el Tripartitum opus iuris consuetudinarii inclyti regni Hungariae, de István Werböczy (ca. 1458-1541), considerado como Derecho patrio, había incluido muchos elementos extranjeros ${ }^{8}$. Otro planteamiento distinto a los anteriores fue el manifestado por Sándor Daempf, que defendió la necesidad de elaborar un nuevo y autónomo Código Civil húngaro.

Tras estos acontecimientos, el destacado romanista y civilista húngaro, Pál Hoffmann (1830-1907), se dedicó a elaborar en el año 1871 el proyecto de la parte general del Código Civil húngaro (“Általános Magánjogi Törvénykönyv”), que le fue encomendado por el entonces ministro de justicia Boldizsár Horváth (1822-1898). El proyecto de Hoffmann sigue en esencia las secciones del Código Civil para el Reino de Sajonia, publicado en 1863 y puesto en vigor en 1865, que reflejaba en gran parte la influencia de Georg Friedrich Puchta (1798-1846). El proyecto fue analizado por la Königliche Tafel (Tribunal Superior) y la Curia (Tribunal Supremo de Justicia), que criticaron su estilo complicado y el anacronismo de algunas de las instituciones jurídicas que aparecían reguladas en el mismo. Un segundo proyecto de la parte general fue elaborado nueve años más tarde, en 1880, por Elek Győry (1841-1902).

9. El siguiente proyecto de código civil se limitó al Derecho de sucesiones. En esta materia, los juristas húngaros adoptaron una posición especialmente conservadora. Ello se manifestó ya en el Congreso de Juristas del año 1861 (que decidió mayoritariamente el cese del Código Civil General austriaco (ABGB.) en Hungría), que conservaba la herencia lineal ("paterna paternis, materna maternis"), esto es, la distinción entre bienes heredados y adquiridos en caso de inexistencia de sucesores, así como también la conservación del fideicomiso familiar (fideicommissum). Los participantes en el

\footnotetext{
7 Véase: A. MESZlÉNY: Országbírói Értekezlet és az Osztrák Polgári Törvénykönyv [Iudexcurialkonferenz y el Código Civil General Austríaco"] Budapest, 1897.

${ }^{8}$ Sobre IstvánWerbőczy véase: Tanulmányok Werbőczy Istvánról - Studien über István Werbőczy. (Hrsg. von G. HAMZA). Budapest, 2001.
} 
Congreso fundamentaron esta decisión en la necesidad de "conservar el producto del genio jurídico creador del pueblo húngaro".

En el año 1871, en el Segundo Congreso Nacional de Juristas, llevado a cabo en la capital del país, István Teleszky (1836-1899) propuso codificar el Derecho sucesorio húngaro antes que la codificación completa; dos años más tarde fue designado por el Ministro de Justicia para la preparación del correspondiente proyecto. En el año 1876, se publicó su obra bajo el título Örökösödési jogunk törvényhozási szabályozásához ("Sobre la técnica legislativa de nuestro Derecho sucesorio"), en la que Teleszky dejó claramente expuestas sus ideas rectoras. Uno de sus puntos de reforma propuestos era derogar la institución feudal de la sucesión por generación. El "Proyecto de un Código General Civil, Derecho sucesorio", compuesto oficialmente en 1882, se basaba en aquellos supuestos, así como igualmente -tanto en su estructura como en su contenidoen el Código Civil para el Reino de Sajonia, de 1863/1865. Él también se inspiraba en el libro titulado: Entwurf eines deutschen Reichsgesetzes über das Erbrecht nebst Motiven (Braunschweig, 1876), de Friedrich Mommsen (1818-1892). Obra ésta que también fue tomada en consideración en el conjunto de los trabajos preparatorios para la codificación del Derecho privado en Alemania iniciados en 1873.

Este proyecto privado de Friedrich Mommsen influyó especialmente sobre las reglas relativas a las disposiciones de última voluntad y legados del proyecto de Teleszky. Además, se debe resaltar que, contrariamente al Código Civil General austriaco, basado en el principio de libertad testamentaria, en el caso del proyecto húngaro, los sucesores legales gozaban de prelación. El proyecto de ley sobre Derecho sucesorio, publicado por la Comisión de Justicia del parlamento húngaro en el año 1889, seguía en todo al proyecto de Teleszky.

10. Al intento de codificación del Derecho de obligaciones, de István Apáthy ${ }^{9}$ (18291889) -que, por lo demás, fue influido por el proyecto del Derecho de obligaciones de Dresde del año 1866, precedente del posterior Código Civil alemán (BGB.)- en materia del negocio jurídico, siguió la teoría de la voluntad ("Willenstheorie") de Savigny. Igual actitud asumió el proyecto de Pál Hoffmann y la "Parte general", redactada por Elek Győry en 1880.

El proyecto sobre los derechos reales de Endre Halmossy, del año 1882, fue, por el contrario, influenciado en menor medida por la pandectística alemana.

Los proyectos en Derecho de familia de este período provienen de las obras de László Sipöcz (Von der Vormundschaft und Pflegschaft, 1891), Benő Zsögöd (Das persönliche Verhältnis der Ehegatten zueinander und eheliches Vermögensrecht, 1891) y Lajos Králik (Von den Eltern und den Kindern, 1892).

El proyecto de Benő Zsögöd (Béni Grosschmid, 1852-1938) tuvo escasas influencias de la pandectística alemana. El señalado autor, en el ámbito de la propiedad y del Derecho

\footnotetext{
${ }^{9}$ István Apáthy (1829-1889) fue el redactor de la primera ley húngara de derechos de autor (Ley 1884: XVI).
} 
sucesorio, fue ante todo un comprometido representante y defensor de la conservación del Derecho privado húngaro (ius patrium), de fuerte influencia feudal.

En resumen, puede decirse que, con la elaboración de múltiples proyectos parciales, al inicio de 1880, se consigue un primer proyecto completo -simple y defectuoso en su contenido- del primer Código Civil. De todos modos, en el año 1894, la parte de las personas, en materia de Derecho matrimonial, fue regulada legislativamente (Ley 1894: XXXI). También resulta preciso mencionar la Ley 1877: XX sobre tutela y la curaduría.

11. La motivación y el impulso para que finalmente se sancionara un Código Civil se pusieron de manifiesto en la política húngara desde 1895. Uno de los seguidores de este movimiento, fue el romanista y civilista húngaro Gusztáv Szászy-Schwarz. Su proyecto de 2043 parágrafos fue concluido en su totalidad en el año 1900, mientras era ministro de Justicia el renombrado procesalista Sándor Plósz (1846-1925). Contrariamente a los anteriores proyectos parciales, este denominado primer proyecto puede calificarse como completo. Tanto en su estructura, como en las instituciones jurídicas que regulaba, resulta posible apreciar una clara y evidente influencia del BGB alemán.

El proyecto constaba de cuatro partes: Personas y Derecho de familia; Derecho de obligaciones; Derechos reales; y Derecho sucesorio. En este trabajo de codificación, la inexistencia de una parte general resulta completada por el primer título del Derecho de obligaciones, equivalente en este caso a una parte general "oculta". Respecto al acto o negocio jurídico, el proyecto sigue la teoría de la declaración ("Erklärungstheorie").

12. El segundo proyecto de un Código Civil, del año 1913 (llamado "Texto de la Comisión del año 1913"), proviene del período en el cual ejerció funciones de Ministro de Justicia Jenő Balogh, quien, lo mismo que su predecesor, Sándor Plósz, fue un renombrado jurista. En los 1980 párrafos de este corto proyecto, se nota una fuerte influencia del BGB alemán, así como también en el proyecto del año 1900. Igualmente este proyecto carecía de una parte general y se estructuraba en los siguientes libros: Personas y Derecho de familia; Derecho de las obligaciones; Derechos reales; y Derecho sucesorio. Así, desde el punto de vista de su estructura, no presentaba ninguna diferencia con el primer proyecto del año 1900. Las corporaciones y fundaciones no aparecen reguladas en este proyecto, sino que fueron objeto de una ley especial. El proyecto prestaba especial atención a la protección de la transferencia y adquisición de buena fe, en tanto contiene modificaciones de carácter ético en comparación con el primero de los proyectos. El Derecho sucesorio era mucho más amplio y abarcaba más partes que el correspondiente proyecto que lo precedió. Las principales innovaciones en Derecho sucesorio atañían al legado real, la administración de la masa sucesoria y la enajenación de la herencia.

13. En el año 1914 se publicó el tercer proyecto (denominado "Texto del Parlamento del año 1914"). En el año 1915 se publicó el cuarto proyecto (denominado "Proyecto de la Comisión del año 1915"). Ambos proyectos contienen sólo pequeñas modificaciones en relación con los de los años 1900 y 1913. El fracaso del tercer y cuarto proyecto de 
Código Civil se debió fundamentalmente al desencadenamiento de la Primera Guerra Mundial.

14. En la elaboración del quinto proyecto del Código de Derecho Privado (Magánjogi törvényjavaslat; abreviado como Mtj.), del año 1928, tuvo una sobresaliente participación Béla Szászy (1865-1931), llamado "el Eugen Huber húngaro"10. El proyecto, compuesto por 2171 parágrafos, surgió mientras ejercía el ministerio de Justicia Pál Pesthy (1873-1952). Este proyecto de codificación del Derecho privado tiene una importante y fuerte influencia del Código Civil (ZGB.) y del Código de las obligaciones (OR.) suizos. En especial, el Código de las obligaciones suizo influyó el proyecto del Código de Derecho Privado (Mtj.) de 1928.

La Pandectística alemana influyó en el Derecho privado húngaro en el ámbito de la responsabilidad independiente de la culpa, o responsabilidad objetiva. Así, en el proyecto del Código Civil húngaro del año 1900, se reguló la responsabilidad bajo la influencia del Código Civil alemán (BGB.), fundado en el principio de la culpa. El $\S$ 1486 del proyecto de 1913, siguiendo al segundo proyecto ("Zweiter Entwurf") de Código Civil alemán del año 1887, reguló el resarcimiento y responsabilidad por daños aún sin culpa. El internacionalmente conocido y ponderado $\S 1737$ del Proyecto de Código Civil (en forma abreviada: Mtj.), de 1928, que regula la responsabilidad por equidad, sigue, en lo esencial, aun cuando no de forma inmediata, al Zweiter Entwurf, en que se reconocía como regla subsidiaria la responsabilidad objetiva como fundamento del resarcimiento de daños.

15. Respecto a la influencia del $M t j$., debe destacarse que fue aplicado por los tribunales húngaros al mismo nivel que el Derecho vigente ("en tanto Derecho consuetudinario escrito"), debido a que la judicatura lo describía con convicción como ratio scripta. Desde este punto de vista, puede reconocerse un gran paralelo entre el quinto proyecto (Mtj.) y el Tripartitum de István Werbőczy. Es más, muchos juristas denominan al proyecto, con razón, como la "carta constitucional del Derecho privado".

El significativo intento de codificación se vio facilitado por una ley (Ley 1931: XXII), que dispuso y posibilitó la discusión parlamentaria del $M t j$. para la sanción y promulgación del Código Civil. De la coordinación para su promulgación se encargó el entonces Ministro de Justicia Tibor Zsitvay (1884-1969). Según esta ley, que regulaba el procedimiento parlamentario, se debía constituir una comisión de 60 miembros, de los cuales 30 debían ser parlamentarios de la cámara baja ("Képviselöház") y alta ("Felsőház"). Es de destacar que en su discurso de apertura de las sesiones del parlamento, el regente, el entonces Jefe del Estado de Hungría, Miklós Horthy (1868-

10 Béla Szászy, doctorado en la Universidad de Budapest en el año 1888, asumió una cátedra extraordinaria de Derecho eclesiástico e Historia del Derecho entre los años 1889-1892 en la Academia de Derecho de la Iglesia Reformada en Kecskemét. De 1892 a 1894 fue juez. A partir de 1894, trabajó en el Ministerio de Justicia. Desde 1918 fue director de la Sección de Elaboración de Leyes del Ministerio de Justicia húngaro, con el rango de secretario. En mayo de 1931 fue elegido como miembro correspondiente de la Academia Húngara de Ciencias. Véase: B. Kolosváry: Szászy Béla levelezö tag emlékezete ["En memoria del miembro correspondiente Béla Szászy"]. Budapest, 1934; también: K. SzLAdITS, Szászy Béla ["Béla Szászy"] Budapest, 1934. 
1957) resaltó que "el Parlamento tenía una tarea que realizar poco frecuente en siglos". En ese mismo año, la crisis económica provocó el cambio de gobierno, dando lugar, por segunda vez, al fracaso del intento de codificación.

16. El Parlamento húngaro no sancionó el proyecto en el año 1931 por razones políticas conyunturales. Sin embargo, a largo plazo, fue decisivo que, después de la Primera Guerra Mundial, en base al Tratado de paz de Trianon, de 4 de junio de 1920, una gran parte del territorio que históricamente había pertenecido a Hungría, fue segregado y anexionado a los Estados vecinos. Estos territorios debían ser excluidos en el período de guerra del ordenamiento del Derecho privado vigente con la sanción de un Código Civil húngaro. En dichos territorios continuaba rigiendo en gran medida el Derecho consuetudinario húngaro no codificado ${ }^{11}$. Como excepción a lo indicado, cabe indicar que en el Estado de Burgenland, que se hallaba anexionado a Austria, el 15 de junio de 1922 entró en vigor el Código Civil General austriaco (ABGB.).

17. Los cinco proyectos surgidos entre los años 1900 y 1928 presentan una misma característica, que se concreta en la circunstancia de que las significativas modificaciones en dichos proyectos, aún con el apoyo de la jurisprudencia húngara, no pudieron ser aceptadas a consecuencia de la inexistencia formal de una sanción parlamentaria de carácter oficial. Sin embargo, estas modificaciones condujeron a una especie de "fuente de leyes especiales del Derecho privado húngaro".

En efecto, el legislador húngaro tomó de los proyectos el material para el trabajo legislativo y sanción de las posteriores leyes, entre otras, sobre responsabilidad en la compra de animales (Ley 1923: X), sobre la hipoteca (Ley 1927: XXXV), sobre Derechos de autor (Ley 1921: LIV) y también sobre la responsabilidad en el hospedaje (Ley 1924: XIII).

18. El primer Código Civil húngaro fue sancionado en el año 1959 (Ley 1959: IV). La Comisión de Codificación fue convocada por el Consejo de Ministros en diciembre de 1953. Entre los miembros de la Comisión se encontraban los representantes de las siguientes instituciones: las cátedras de Derecho civil de las tres Facultades de Derecho de las Universidades de Budapest, Pécs y Szeged; la cátedra de Derecho de la Universidad de Economía de Budapest; la Sección de Derecho civil del Instituto de Estado y Ciencias Jurídicas de la Academia de Ciencias Húngara; el Tribunal Superior de Justicia; y el Fiscal Superior del Estado, como representante del Ministerio de Justicia.

El primer proyecto fue concluido en 1956. Tras la primavera de 1957, los miembros de la Comisión creada por el Ministro de Justicia se ocuparon de los principales interrogantes del proyecto, dando lugar a uno modificado en el año 1957. Este proyecto fue publicado y sometido a discusión pública. El texto definitivo, que fue realizado por una nueva Comisión creada por el Ministerio de Justicia, fue presentado como proyecto

\footnotetext{
${ }^{11}$ También se debe aclarar que muchas partes del Derecho privado húngaro fueron reguladas por leyes especiales.
} 
de ley al Parlamento y sancionado en el año 1959. El primer Código Civil húngaro entró en vigor el 1 de mayo de 1960.

19. Dicho primer Código Civil húngaro reflejaba, en su versión originaria, pese a la fuerte influencia de la ideología marxista, entre otras, la influencia del Código Civil suizo y Derecho de las obligaciones suizo, del Código Civil alemán y del (quinto) Proyecto de Código Civil húngaro del año 1928 (Mtj.). De los códigos civiles de los estados socialistas, los miembros de la Comisión tuvieron en cuenta el Código Civil de la Rusia Soviética del año 1922, el (primer) Código Civil checoslovaco del año 1950, el Proyecto de Código Civil polaco del año 1955, La Ley sobre obligaciones y contratos búlgara del año 1950 y la Ley sobre propiedad búlgara del año 1951.

Este primer Código Civil húngaro carecía de una parte general, estableciéndose en su lugar una serie de disposiciones generales en siete parágrafos. El código estába conformado por las siguientes partes: Disposiciones introductorias; Derecho de las personas (la persona natural como sujeto de Derecho, el Estado como sujeto de Derecho, la persona jurídica, la protección civil de las personas); propiedad (y derechos reales); Derecho de obligaciones; Derecho sucesorio; y Disposiciones finales. En muchas instituciones jurídicas se reflejaba la influencia inmediata del Derecho romano.

20. El Código Civil húngaro no utilizaba el concepto de derecho real ni la limitada noción de Derecho de las cosas. Igualmente, regulaba el contenido de las diferentes formas de propiedad (como la propiedad estatal, la propiedad de cooperativas, la denominada "propiedad personal" y, de forma muy limitada, lo vinculado con la existente propiedad privada), todo ello impregnado por lo indicado por Ulpiano respecto a los poderes del propietario (uti, frui, habere, possidere, abuti). En el ámbito de la posesión, el Código Civil húngaro sólo conocía la possessio civilis, pero no la possessio naturalis (detentio).

La protección de la posesión no estuvo inicialmente regulada en la ley, y sólo fue reconocida con posterioridad por la práctica jurisprudencial. Respecto a la transferencia de la propiedad, el Código Civil húngaro siguió el principio tradicional, es decir, además de la causa (causa o titulus) se exigía la entrega de la cosa (traditio). La prescripción adquisitiva (usucapio) no fue establecida siguiendo el Derecho romano, porque el primer Código Civil húngaro sólo exigió como requisito el de la cosa susceptible de posesión (res habilis), pero no requería la buena fe (bona fides) ni una causa como justo título (iustus titulus o iusta causa). Las servidumbres (servitutes) se reconocieron como derechos autónomos de uso (usus).

21. La parte correspondiente al Derecho de obligaciones (parte IV) del Código Civil del 1959 siguió el sistema de las Pandectas, estructurándose en una parte general y otra especial. De la misma forma, y en ello es contrario al Código Civil alemán, se rechazaba la distinción entre negocio jurídico unilateral y bilateral. En el Derecho de los contratos, los redactores del Código Civil húngaro siguieron a la teoría de la declaración ("Erklärungstheorie"). De acuerdo con la regula Catoniana, se podía solicitar sin limitación temporal la nulidad del contrato ("quod initio vitiosum est non potest tractu 
temporis convalescere"). El Derecho de prenda aparecía regulado como garantía de las obligaciones dentro del Derecho de obligaciones, reconociéndose además el pignus Gordianum (Derecho de prenda para relaciones de tracto sucesivo y duraderas).

Por influencia del Derecho romano también se regularon las distintas obligaciones naturales (por ejemplo los créditos surgidos de juegos y apuestas). Dentro del Derecho de obligaciones (en el capítulo XXXV) asimismo se regularon los contratos de planificación ("Planverträge"). Este capítulo, sin embargo, dejó de ser aplicado después de la reforma económica en el año 1968, para, finalmente, terminar siendo derogado formalmente en el año 1977.

El Derecho húngaro de sucesiones encuentra sus raíces en el Derecho romano o tradición jurídica romana. El Código Civil húngaro conoce, sin embargo, sólo la sucesión ipso iure, y no considera -como, por ejemplo, lo hace el Código Civil General austriaco- la herencia yacente (hereditas iacens).

22. El Código Civil húngaro, entre los años 1967 y 1977 -ante todo por el cambio del sistema político-económico- resultó impregnado por la ideología marxista en sus disposiciones, confrontándose a los postulados de la economía libre de mercado. Mientras que algunas reformas del Código Civil húngaro modificaban su carácter fundamental (así, por ejemplo, la Ley 1991: XIV y la Ley 1993: XCII), otras innovaciones afectaron sólo a algunas instituciones jurídicas. En la Ley 1991: XIV se regularon la nulidad de los contratos contrarios a las buenas costumbres (contractus contra bonos mores) y se introdujo el principio de la buena fe. Desde el año 1996 existe la hipoteca sobre cosas muebles, lo que del mismo modo significa un retorno a la tradición jurídica romana.

23. La circunstancia de que el Código Civil húngaro del año 1959 -si bien con modificaciones- se haya adaptado tanto al fundamento jurídico de la "economía de mercado socialista", así como también al sistema de economía libre de mercado, se explica porque sus redactores dieron mucho valor a los elementos constantes del Derecho civil -en manifiesto contraste, por ejemplo, con los redactores del Código civil (Zivilgesetzbuch) de la República Democrática Alemana del año 1975- y poca entrada a disposiciones impregnadas ideológicamente. De esta forma, se confirma en el Código Civil húngaro la tesis de Karl Renner sobre "la neutralidad del Derecho".

Tras la promulgación del Código Civil húngaro -en consonancia con la secularmente larga tradición húngara- la jurisprudencia, ante todo del Tribunal Supremo de Justicia ("Legfelsőbb Bíróság"), ha desempeñado un papel creador importante.

24. Varias ramas del Derecho privado fueron codificadas, no en el Código civil húngaro, sino en leyes especiales, en atención al concepto socialista de las llamadas "ramas del Derecho" $^{12}$. El Derecho de familia fue regulado por la ley sobre matrimonio, familia y

\footnotetext{
${ }^{12}$ Véase: G. HAMZA, The Classification (divisio) into 'Branches' of Modern Legal Systems (Orders) and the Roman Law Tradition, en European Journal of Legal Reform 8 (2006), pp. 361-382; IDEM, Die Untergliederung der modernen Rechtssysteme und die römischrechtliche Tradition, en Seminarios
} 
tutela del año 1952. Esta ley fue reformada en varias ocasiones, incluso ante el cambio de sistema político y económico que tuvo lugar en los años 1989/1990; así, por ejemplo, en el año 1987. El Código del Trabajo del año 1967 (el Derecho del trabajo fue regulado hasta entonces sólo a través de reglamentos) fue modificado igualmente varias veces, hasta llegar a ser sustituido por un nuevo Código del Trabajo en el año 1992.

La "propiedad intelectual" se reguló inicialmente en una ley del año 1969, que fue sustituida con posterioridad por una nueva ley en 1999. El "decreto-ley" ("törvényerejü rendelet") sobre Derecho internacional privado proviene del año 1979 (decreto-ley nr. 13 de 1979). Las corporaciones se regularon en las leyes 1992:I, 2000:CXLI y 2004:IV.

\section{EL CÓDIGO CIVIL DEL 2013}

1. A lo largo de la elaboración ${ }^{13}$ de la nueva codificación del Derecho privado húngaro (Derecho civil, Derecho comercial, Derecho societario) se asumieron diferentes puntos de vista en relación con el Derecho societario (comercial), cuestionándose si debía ser regulado en forma independiente o integrado en la codificación ${ }^{14}$. Esta discusión se sustancia en la relatitiva aceptación o rechazo de un Code unique.

El fundamento jurídico para una nueva codificación estatal integrada fue el Decreto del gobierno $\mathrm{N}^{\circ}$ 1050/1998, modificado posteriormente por otro, el $\mathrm{N}^{\circ} 1061 / 1999$. La Comisión Central de Codificación adoptó, en su sesión del 8 de noviembre del 2001, el "Proyecto del Nuevo Código Civil Húngaro " (Az új Polgári Törvénykönyv koncepciója). Con el Decreto del gobierno $\mathrm{N}^{\circ} 1009 / 2002$, el proyecto fue publicado el 31 de enero de $2002^{15}$. Mediante el Decreto del gobierno $\mathrm{N}^{\circ} 003 / 2003$ se dio por terminada la elaboración de un texto legal concreto.

Debe resaltarse que el segundo Código Civil, es decir, el nuevo Código, es un code unique, al igual que también lo son, por ejemplo, el (segundo) Codice civile italiano del año 1942, o el nuevo Código Civil holandés (Nieuw Burgerlijk Wetboek).

2. El Código Civil del 2013 no contiene una parte general y presenta la siguiente estructura: Disposiciones introductorias (libro I); Hombre, como sujeto del derecho (libro II); persona jurídica (libro III); Derecho de familia (libro IV); derechos reales (libro V); Derecho de obligaciones (libro VI); Derecho de sucesiones (libro VII); y

Complutenses de Derecho Romano. Revista internacional de Derecho romano y tradición romanística XXII (2009) pp. 191-223.

13 Para su trasfondo teórico véase: L.VÉKÁS, Az új Polgári Törvénykönyv elméleti előkérdései ["Presupuestos teóricos para el nuevo Código Civil"] Budapest, 2001.

${ }^{14}$ Véase: L. VÉKÁs, Szükség van-e kereskedelmi magánjogra? ["Es necesario un nuevo Derecho privado comercial"], en Magyar Jog ["Derecho Húngaro"] 44 (1998) pp. 705-714.

${ }^{15}$ Véase: Magyar Közlöny ["Diario Oficial húngaro], 2002/15: Az új Polgári törvénykönyv koncepciója. Cfr. L. VÉKÁS, Az új Ptk. koncepciója és tematikája ["Concepto y temática del nuevo Código Civil húngaro"], en Magyar Közlöny különszám ["Edición especial del Diario Oficial húngaro"], Budapest, 10 de febrero del 2003. 
Disposiciones finales (libro VIII). El proyecto de nuevo Código Civil húngaro, en contraposición al Código Civil del año 1959, regula también el Derecho de familia.

El Código Civil del 2013 entró en vigor el 15 de marzo 2014.

3. La Comisión Central de Codificación adoptó el concepto monista (concept moniste). En relación con el nuevo Código Civil húngaro rigen, por ejemplo, las disposiciones generales del Derecho de obligaciones, cuyas reglas son aplicadas de forma uniforme e indistinta a comerciantes y no comerciantes. Sin embargo, se aplican ciertas disposiciones especiales para los consumidores, en tanto los redactores incorporaron las nuevas corrientes en materia de Derecho europeo de protección de consumidores. El concepto monista también tiene relevancia, puesto que las reglas generales de Derecho privado en relación con las sociedades comerciales se encuentran igualmente contenidas en el nuevo Código Civil húngaro (en la parte correspondiente a personas jurídicas) ${ }^{16}$.

El Derecho del trabajo continúa siendo regulado en un código autónomo (Ley 2012: I) que sustituyó al Código del Derecho de Trabajo del 1992 (Ley 1992: XXII). La reglamentación de la protección del consumidor se halla en la Ley 1997: CLV.

En el Código Civil húngaro del 2013 las reglas generales del Derecho de los contratos son aplicables como materia jurídica singular, es decir, como fuente del contrato individual de trabajo.

Parte de la regulación concerniente a la "propiedad intelectual", como, por ejemplo, es el caso de los contratos de uso de elaboraciones intelectuales, también aparecen incluidos en el nuevo Código Civil húngaro.

4. Los redactores no se orientaron por un único código civil extranjero. Por ello, el nuevo Código Civil holandés (Nieuw Burgerlijk Wetboek) no puede ser considerado como su único modelo. Los redactores tuvieron en cuenta, entre otras fuentes, la Convención de Viena sobre compraventa internacional, del año 1980, los Principios Unidroit, los Principles of International Commercial Contracts del año 1994 y los Principles of European Contract Law, del año 1997. También tomaron en consideración el Derecho privado comunitario europeo ${ }^{17}$, a consecuencia de la entrada de Hungría en la Unión Europea (UE) el primero de mayo del 2004.

La circunstancia de que Hungría, como único Estado reformista de Europa central y oriental, no haya sancionado una nueva Constitución hasta el año $2012^{18}$ por falta de un

\footnotetext{
${ }^{16}$ Véase: Szakértői javaslat az új Polgári Törvénykönyv tervezetéhez ["Propuesta de los expertos de un nuevo Código Civil para Hungría"] (Red. L. VÉKÁs) Budapest, 2008.

${ }^{17}$ En relación con el concepto de la existencia del Derecho privado comunitario europeo, en formación, véase una completa bibliografía en P.-Chr. MüLLER-GRAFF, Privatrecht und europäisches Gemeinschaftsrecht. Gemeinschaftsprivatrecht $2^{\text {a }}$ edición, Baden-Baden, 1991.

${ }^{18}$ La constitución (Ley Fundamental) de Hungría fue adoptada por el Parlamento unicameral en el año 2011. La Ley Fundamental (en húngaro: „Alaptörvény”) de Hungría entró en vigor el 1 de enero de 2012. Respecto a las características principales de la constitución (Ley Fundamental) del 2011 de Hungría véase: G. HAMZA, I principi alla base della nuova Costituzione ungherese en M. P. Baccari Vari (a cura): I fondamenti del diritto europeo e la nuova Costituzione ungherese, Modena, 2014 pp. 45-52.
} 
consenso político, no representó ningún obstáculo para el actual desarrollo de los trabajos de codificación ${ }^{19}$.

5. El Código de Comercio húngaro (Kereskedelmi Törvénykönyv), del año 1875 (Ley 1875: XXXVII), siguió el modelo del primer Código General de Comercio alemán (Allgemeines Deutsches Handelsgesetzbuch; abreviado: ADHGB.), del año 1861. Por ello, el legislador húngaro siguió el concepto dualista (concept dualiste). Este concepto dualista no se ha modificado, aun cuando Hungría sancionó su Código Civil en el año $1959^{20}$. El Código de Comercio húngaro del 1875 rigió, en su versión reformada, hasta finaless de los años 40 del siglo XX, aunque sus reglas sobre sociedades mercantiles permanecieron vigentes incluso hasta el día primero de enero de 1989.

6. Una nueva ley de reforma sobre las "sociedades económicas" (Törvény a gazdasági társaságokról) fue sancionada en Hungría en el año 1988, y entró en vigor el 1 de enero de 1989 (Ley 1988: VI). Esta ley reemplazó el Código de Comercio húngaro de 1875 y ha colaborado significativamente con el cambio del sistema económico del país. La novedosa Ley sobre sociedades económicas, del año 1997 (Ley 1997: CXLIV), fue derogada y reemplazada por una nueva ley el 1 de julio del año 2006 (Ley 2006: IV). ${ }^{21}$ Esa ley fue derogada por el nuevo Código Civil del 2013.

\section{BIBLIOGRAFÍA}

BRAUNEDER, Europas erste Privatrechtskodifikation: Das galizische Bürgerliche Gesetzsbuch, en Barta, Heinz et alii Naturrecht und Privatsrechtskodifikation. Martini Colloquium 1998, Wien, 1999.

- Das Allgemeine Bürgerliche Gesetzbuch für die gesammten Deutschen Erbländer der österreichischen Monarchie von 1811, en Gutenberg-Jahrbuch 62, Mainz, 1987.

\footnotetext{
${ }^{19}$ Una visión sobre los resultados actuales de la reforma del Derecho privado húngaro puede verse en un artículo de L. VÉKÁs, Über die umfangreiche Reform des ungarischen Zivilrechts., en Gedankenaustausch zwischen deutschen und ungarischen Juristen. Konferenzbeiträge 1997-2003 Budapest, 2004, pp. 418-432. Vékás era Presidente de la Comisión para la Nueva Codificación del Derecho Privado Húngaro. Sobre la reforma del Código Civil húngaro puede verse: Zeitschrift für Rechtsvergleichung, Internationales Privatrecht und Europarecht 45 (2004), pp. 65-73.

${ }^{20}$ En la doctrina también hay posiciones contrarias, según las cuales la codificación separada del Derecho comercial no tendría ningún sentido. Véase: B. GrossCHMID, A kereskedelmi jognak különválásáról ["Sobre la separación del Derecho comercial"]; en IDEM, Magánjogi tanulmányok [Estudios de derecho privado] Budapest, 1901, pp. 719-725. Grosschmid se fundamenta principalmente en el Derecho de las obligaciones para seguir el concepto monista.

${ }^{21}$ Hay que añadir que la Ley 2006: V sobre las reglas procesales respecto a las sociedades comerciales (mercantiles) se encuentra en vigor.
} 
DESPUT -KOCHER: Franz von Zeiller: Symposium der Rechtswissenschaftlichen Fakultät der Universität Graz und der Steiermärkischen Landesbibliothek am 30. November 2001 aus Anlass der 250. Wiederkehr seines Geburtstages. Graz, 2003 y

GROSSCHMID, A kereskedelmi jognak különválásáról ["Sobre la separación del Derecho comercial"]; en Idem, Magánjogi tanulmányok [Estudios de derecho privado] Budapest, 1901, pp. 719-725.

HAMZA: Entstehung und Entwicklung der modernen Privatrechtsordnungen und die römischrechtliche Tradition. Budapest, 2009. pp. 381-388.

- The Classification (divisio) into 'Branches' of Modern Legal Systems (Orders) and the Roman Law Tradition, en European Journal of Legal Reform 8 (2006).

- Die Untergliederung der modernen Rechtssysteme und die römischrechtliche Tradition, en Seminarios Complutenses de Derecho Romano. Revista internacional de Derecho romano y tradición romanística XXII (2009).

- I principi alla base della nuova Costituzione ungherese en M. P. Baccari Vari (a cura): I fondamenti del diritto europeo e la nuova Costituzione ungherese, Modena, 2014.

HEBEIS, Karl Anton von Martini 1726-1800. Leben und Werk. Frankfurt am Main, 1996.

KOLOSVÁRY: Szászy Béla levelező tag emlékezete ["En memoria del miembro correspondiente Béla Szászy"]. Budapest, 193.

MESZLÉNY: Országbírói Értekezlet és az Osztrák Polgári Törvénykönyv [Iudexcurialkonferenz y el Código Civil General Austríaco"] Budapest, 1897.

MÜLLER-GRAFF, Privatrecht und europäisches Gemeinschaftsrecht. Gemeinschaftsprivatrecht $2^{\mathrm{a}}$ edición, Baden-Baden, 1991.

SCHILLER, Franz Anton von Zeiller als Gesetzgeber und Begründer einer bürgerlichen Rechtskultur. en K. Acham (ed.): Rechts-, Sozial- und Wirtschaftswissenschaften aus Graz. Wien, 2011. pp. 289-312.

SZLADITS, Szászy Béla ["Béla Szászy"] Budapest, 1934.

TÓTH, Emlékbeszéd Zsivora György felett ["Discurso en memoria de György Zsivora"] Budapest, 1884.

VÉKÁS, Az új Polgári Törvénykönyv elméleti elökérdései ["Presupuestos teóricos para el nuevo Código Civil"] Budapest, 2001.

Szükség van-e kereskedelmi magánjogra? ["Es necesario un nuevo Derecho privado comercial"], en Magyar Jog ["Derecho Húngaro"] 44 (1998). 
Az új Ptk. koncepciója és tematikája ["Concepto y temática del nuevo Código Civil húngaro"], en Magyar Közlöny különszám ["Edición especial del Diario Oficial húngaro"], Budapest, 10 de febrero del 2003.

Über die umfangreiche Reform des ungarischen Zivilrechts., en Gedankenaustausch zwischen deutschen und ungarischen Juristen. Konferenzbeiträge 1997-2003 Budapest, 2004, pp. 418-432.

WILHELM, Gesetzgebung und Kodifikation in Frankreich. Ius Commune 1 (1967) y A.-J. Arnaud, Origines doctrinales du Code civil français. Paris, 1969.

Zeitschrift für Rechtsvergleichung, Internationales Privatrecht und Europarecht 45 (2004), pp. 65-73. 